\title{
Virtual Testing of Composite Structures Made of High Entropy Alloys and Steel
}

\author{
Victor Geantă ${ }^{1}$, Tudor Cherecheș ${ }^{2}$, Paul Lixandru ${ }^{2}$, Ionelia Voiculescu ${ }^{3}$, Radu Ștefănoiu ${ }^{1, *}$, \\ Daniel Dragnea ${ }^{2}$, Teodora Zecheru ${ }^{4}$ and Liviu Matache ${ }^{4}$ \\ 1 Faculty of Materials Science and Engineering, Politehnica University of Bucharest, \\ 313 Splaiul Independenţei, 060042 Bucharest, Romania; victorgeanta@yahoo.com \\ 2 UPS PILOT ARM, 2 Laminorului Street, 137210 Târgoviște, Romania; tudor.chereches@yahoo.com (T.C.); \\ paullixandru@yahoo.com (P.L.); danieldrg2003@yahoo.com (D.D.) \\ 3 Faculty of Engineering and Management of Technological Systems, Politehnica University of Bucharest, \\ 313 Splaiul Independenţei, 060042 Bucharest, Romania; ioneliav@yahoo.co.uk \\ 4 Scientific Research Center for CRBN Defense and Ecology Bucharest, Bucharest, 225 Olteniței Road, \\ 041309 Bucharest, Romania; teodora.zecheru@yahoo.com (T.Z.); mliviucris@yahoo.com (L.M.) \\ * Correspondence: radu.stefanoiu@upb.ro; Tel.: +40-744-606-588
}

Received: 19 September 2017; Accepted: 8 November 2017; Published: 11 November 2017

\begin{abstract}
High entropy alloys (HEA) are metallic materials obtained from a mixture of at least five atomic-scale chemical elements. They are characterized by high mechanical strength, good thermal stability and hardenability. AlCrFeCoNi alloys have high compression strength and tensile strength values of $2004 \mathrm{MPa}$, respectively $1250 \mathrm{MPa}$ and elongation of about $32.7 \%$. These materials can be used to create HEA-steel type composite structures which resist to dynamic deformation during high speed impacts. The paper presents four different composite structures made from a combination of HEA and carbon steel plates, using different joining processes. The numerical simulation of the impact behavior of the composite structures was performed by virtual methods, taking into account the mechanical properties of both materials. For analyzing each constructive variant, three virtual shootings were designed, using a $7.62 \times 39 \mathrm{~mm}$ cal. incendiary armor-piercing bullet and different impact velocities. The best ballistic behavior was provided by the composite structures obtained by welding and brazing that have good continuity and rigidity. The other composite structures, which do not have good surface adhesion, show high fragmentation risk, because the rear plate can fragment on the axis of shooting due to the combination between the shock waves and the reflected ones. The order of materials in the composite structure has a very important role in decreasing the impact energy.
\end{abstract}

Keywords: HEA; high entropy alloys; composite structures; dynamic loads; simulation

\section{Introduction}

Metallic materials used for the manufacturing of individual or collective protection components must have high values of breaking and flow boundaries, hardness and elongation at fracture, and also capacity to absorb impact energy. Current military specifications recommend minimum hardness values of 540-600 BHN (Brinell) or 55-60 HRC (Rockwell). Furthermore, the yield stress must be over $1500 \mathrm{MPa}$, tensile strength above $1700 \mathrm{MPa}$, elongation at fracture of at least $6 \%$, and a breaking energy by Charpy-V shock of about $13 \mathrm{~J}$ at $-40{ }^{\circ} \mathrm{C}$ [1].

These requirements are met by designing appropriate chemical compositions of metallic alloys, high strength microalloyed steels being often used for these applications. Studies have shown that material hardness is not a sufficient factor to ensure maximum resistance to the penetration of projectiles 
and that the limit values of compressive and tensile strength are more important in the case of applications in dynamic conditions [2-6].

High-strength low alloy steels are commonly used for making armor components for both military and civil applications, since they possess high hardness and tenacity mechanical properties [7]. The microstructure of the material can provide helpful information for assessing its behavior during dynamic deformation, allowing the study of its ability to reduce or stop armor piercing by projectiles. In the case of steels containing martensite and residual austenite in their microstructure, the dynamic impact behavior is determined by the residual austenite content. Therefore, larger martensite grain sizes and residual austenite amounts result in lower impact resistance of the material [7].

Another type of steel that underwent dynamic tests is the composite microstructure steel, consisting of ferrite $(50 \%)$, bainite $(40 \%)$, and metastable residual austenite $(10 \%)$, known in the literature as TRIP steel [8]. It was found that, during plastic deformation, the residual austenite of these steels transforms into martensite $\left(\alpha^{\prime}\right)$, leading to the obtainment of high compressive strength and hardness, combined with excellent ductility. These features help to dissipate impact energy and to obtain good behavior at dynamic loads.

A new class of alloys which can be used for ballistic protection is high entropy alloys (HEA) [9]. By definition, high entropy alloys contain at least five main metallic elements with concentrations ranging from 5 to $35 \%$ atomic. High entropy alloys (HEA) are composed of $n$ major alloying elements with $n \geq 5$, introduced in equimolar or nearly equimolar ratios, which easily lead to the formation of simple solid phase solutions with BCC or FCC, nano-structures or even amorphous states as cast. Therefore, the high entropy alloys are solid solutions with high strength, good thermal stability and hardening capacity above classical alloys, combined with superior strength characteristics under various environmental conditions [10-13]. Due to excellent mechanical properties, high entropy alloys from the system $\mathrm{AlxCrFeCoNi}$ can be used successfully to create composite structures containing both metallic and ceramic plates, which resists at dynamic load during high speed impacts [9].

Since the micro-structural stability depends on chemical composition, grain size, temperature, and speed testing [8] in applications subjected to dynamic impact, a high level of the main mechanical characteristics must be provided.

In special applications, as the type of composite structures loaded under a dynamic regime, in order to have the best possible behavior at impact, the following features are requested:

- Higher hardness, as a measure of resistance of solid materials to the penetration in surface of various types of penetrators, with permanent changes of shape when a static or dynamic force is applied to them; the macroscopic hardness is generally characterized by the nature and strength of inter-molecular links, the behavior of the solid material under the force action being complex;

- High tenacity at low temperatures, because it represents the ability of the metallic material to absorb the breaking energy, to oppose the emergence and spread of various types of cracks, accumulating the energy necessary for the formation of surface rupture and for the fast local deformation under shock conditions;

- High impact resistance, which is the relative susceptibility to damage by the action of forces applied at high speed.

Currently, most ballistic protection structures are made entirely of composite materials or incorporate, in part, material with outstanding features of impact resistance. The design and implementation of new structures for ballistic protection is based on the knowledge of the required properties of materials and the creation of composite structures for specific conditions of use (such as fast deformation, violent impact and high temperatures, explosion, perforation etc.).

Because of their great diversity, composite structures are being increasingly used in various fields such as aeronautics, automotive, civil or military engineering, energy and electronics, bio-medicine, etc. Current military technologies are oriented mainly towards the field of composite materials and structures, especially those which show superior performance. 
Of these, layered materials are preferred because the special arrangement of layers gives them different values of mechanical characteristics in different directions, making it difficult to clearly identify the matrix and reinforcement through simple sections. Thus, some of the component layers may be, in turn, composite materials reinforced with fibers, which provide additional mechanical properties [9,14-20]. A typical example is the use of textile-carbon reinforcement in cementitious matrices [21].

Generally, in order to provide individual and collective ballistic protection, there are used several types of composite structures, such as metal-composite material hybrid armor, metal-ceramic material hybrid armor, metal-ceramic material-composite material hybrid armor, austenite steel-ultra-high-performance concrete [22-25]. The present research presents a novelty in the domain of composite structure used for ballistic protection: composite structures made from a combination of HEA and carbon steel plates, using different joining processes. The numerical simulation of impact behavior of the proposed composite structures was performed by virtual methods in order to assess the performance of the proposed structures.

\section{Material Models for Virtual Ballistic Testing}

The testing methods of the ballistic structures to highlight the performance of impact resistance can be developed both by direct experimental research, in which one can identify the mechanical behavior of materials embedded inside the protection systems or the perforating ammunition, and by programs for the simulation and modeling of the dynamic processes.

Material models (laws of material) are used for simulating impact phenomena and for highlighting the ballistic processes, the most famous being the Johnson-Cook law and the Zerilli-Armstrong law. According to the tests conducted on materials, a number of algorithms for the calibration and evaluation thereof were developed.

The algorithms of this type have, as a basis, the initialization of some values of material coefficients, making consecutive iterations, followed by calculations or simulations comparing the results with the values obtained from experimental measurements and tests. The procedures for determining the coefficients of material involve a first stage of experimentation and extraction of material characteristics using the Split Hopkinson Pressure Bar (SHPB) method, followed by the validation of these characteristics made by comparing the values obtained in the Taylor test with those calculated by numerical simulations based on the determined material coefficients [22,23].

The simulation and modeling methods allow the qualitative and quantitative study of the most complex mechanical, physical, and chemical processes and phenomena. Through them, the system dynamic development and behavior could be estimated. In the area of materials science, the simulations allow researchers to determine the outcome of the material-system interaction in dynamic conditions, such as the impact relation between projectile and target.

The Split Hopkinson Pressure Bar (SHPB) is the most widely used method to describe the results of different material samples exposed to medium and high speed shaping [26-31]. The best described SHPB process induces unidirectional pressure in the target sample by the simultaneous opposing impact of two bars.

The impact generates an elastic wave in the impacting bar which is partially transferred to the sample and partially reflected by the transition bar. Sensors installed at the ends of the bars measure the generated energy, and the results will allow the shaping of the energetic phenomena and the estimation of the generated forces. The SHPB method has data accuracy shortfalls related to noise levels, characteristic wave length dispersions, and a number of other specific characteristics [32-34].

The mathematical simulation using a limited number of preset characteristics offers the possibility to study the impact and deformation process in real time and to estimate the area of the target crack by analyzing the depth of the penetration, calculating the residual speed of the projectile or fragments, calculating the deceleration profile as function of the initial launching speed. 
The characteristics of the impact area, cracks, craters, and adjacent zones generally agree with the simulation data, leading to a good description of the complex interaction between the projectile and the target [35].

An alternative to dynamic or static simulations is provided by compression tests. Static or dynamic compression tests permit the design and use of SHPB to study the deformation gradient at various values of temperature.

Using lanthanum cylindrical specimens and employing the Johnson-Cook (J-K) equations, the specific deformation characteristics could be easily calculated. J-K compression equations calculated in the SHPB tests for the lanthanum sample were calibrated through numeric simulations and the results confirmed large deformations when exposed to complex pressure tests.

Based on the static and dynamic test results (MTS) using the pulling test on a divided Hopkinson lanthanum sample, the tractor J-K equations were calculated. The reflected and transferred wave of the PSHB tests resulted from the numeric simulation for the lanthanum sample, using the speed of deformation as function of crack failure, confirmed by the subsequent experiments. The relationship between the dynamic crack failure and the speed of the tractor force was pointed out as critical. SEM analysis of the fractured surface showed that the crack failure mechanism becomes erratic with increased speed of the applied effort [36].

One objective of the other study was to model the mass loss of the projectile nose when the projectile hits a defined target at high velocity. The use of a semi-empiric model revealed that the mass loss percentage is linear, depending on the projectile speed, and the depth of the penetration is directly dependent on the projectile nose mass loss [37]. The quantitative evaluation of the physical, chemical, mechanical, etc. phenomena and processes can be successfully done by numeric simulation and mathematical modeling.

\section{Virtual Testing Campaign}

For virtual testing of composite structures, were analyzed two types of metallic materials: high entropy alloys (HEA) from the AlCrFeCoNi system and steels for armor, considering the mechanical properties of both materials $[9,17,20,38]$. Thus, bi-metallic composite structures for ballistic protection plated by explosion, composite structures obtained by brazing, and composite plates welded to outline and sandwich type composite structures, were designed as shown in Figures 1-4.

In the case of the structure welded by explosion (Figure 1), made of steel plate and high-entropy alloy (HEA) plate, the welding of the two materials is accomplished by high pressure diffusion (higher than 10,000 MPa). Impurities and other undesirable products on the contact surfaces are ejected in the direction of the shock wave movement.

Explosion welding is produced under the action of the pressure developed by the detonation products on the impact plate. Several moments selected during the application of the explosion welding technology are shown in Figure 5. The image selection time step is $5 \times 10^{-3} \mathrm{~ms}$.

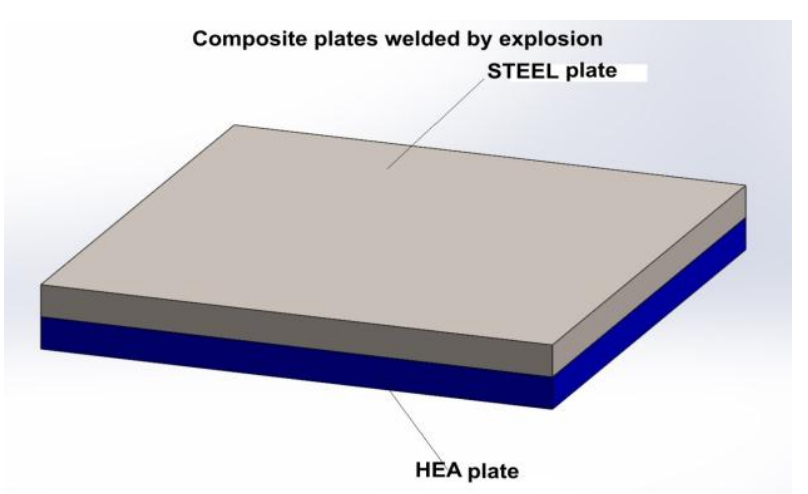

Figure 1. Composite plate welded by explosion. 


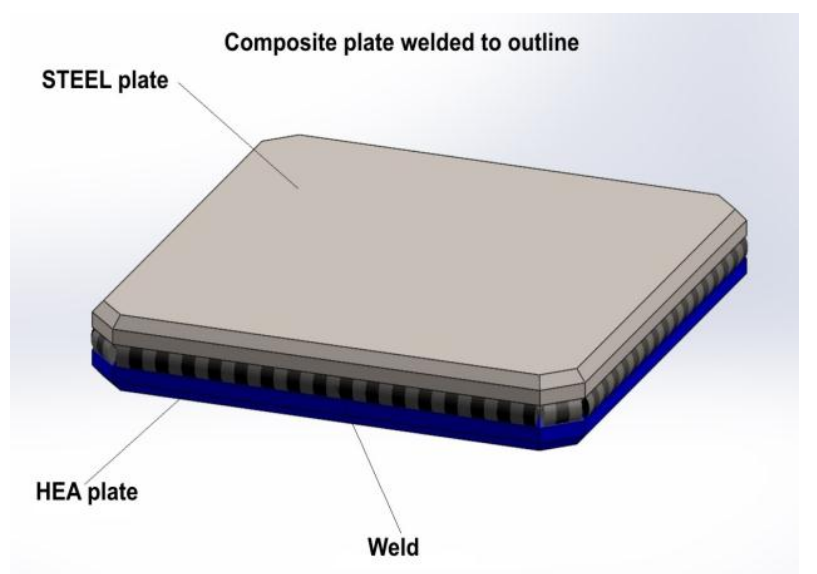

Figure 2. Composite plates welded to outline.

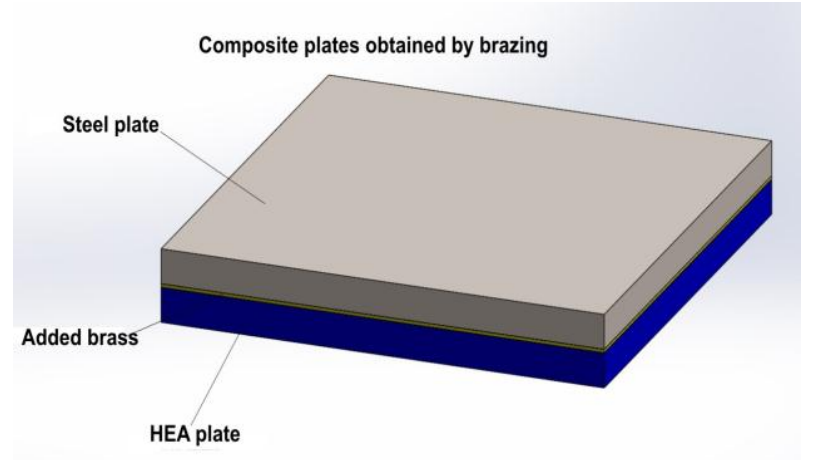

Figure 3. Composite plate obtained by brazing.

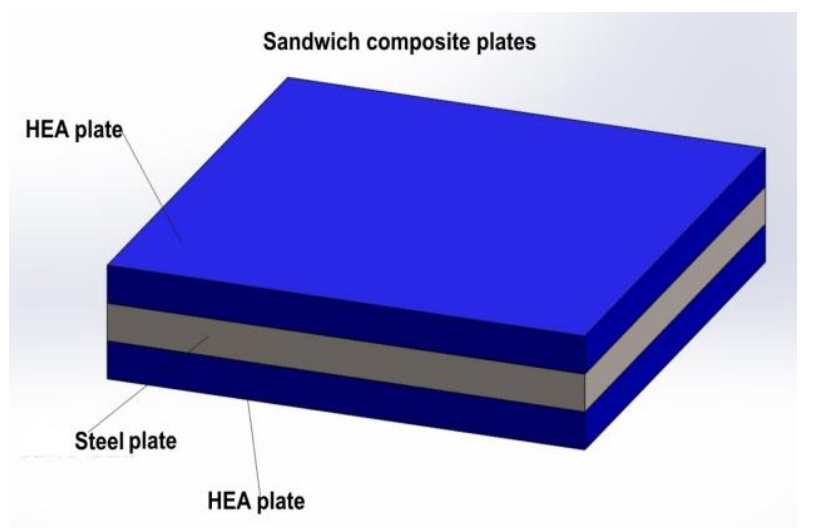

Figure 4. Sandwich composite plates.

The bimetallic plate welded by explosion is calibrated to thickness by hot rolling. The final shape of the plate, depending on its destination, is achieved by hot and cold plastic deformations. Thermal treatments for increasing resistance and toughness are compatible. In the case of the structure variant 2 (Figure 2), the structure is made up of a steel plate and a high entropy alloy (HEA) plate, which are welded on the contour.

In the case of the structure presented in Figure 3, the structure consists of a steel plate and a high entropy alloy plate, which are joined by brazing with brass. In the case of Figure 4 , the structure is 
made of high entropy alloy plate, a steel plate, and another high entropy alloy plate, which are joined together in a sandwich type structure.

In order to limit the production costs, the experiments on the constructive solutions of composite structures were done by virtual numerical simulation methods. The properties of the HEA material are those of the best performance, high strength, and tenacity. For the steel plate, a medium-strength and good tensile material was chosen (low alloyed steel).

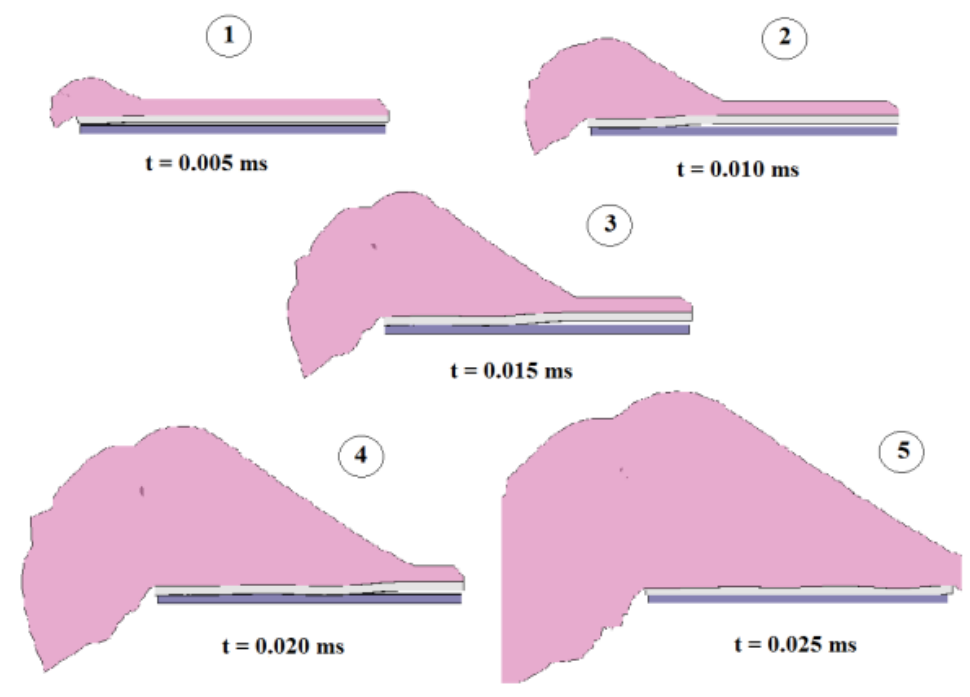

Figure 5. Composite plate welded by explosion.

The structured mesh network, with variable pitch, is very often used to construct finite element models of structural parts, analyzed by the proposed methodology. Using this procedure, the components of the incendiary armor piercing bullet (Figure 6) and those of the composite structure (Figure 7) were discretized.

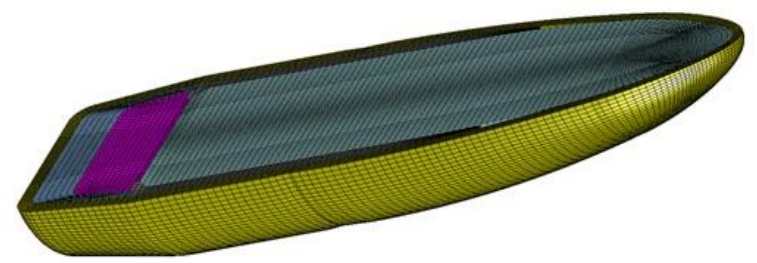

Figure 6. The mesh model with finite elements for the incendiary armor piercing bullet, $7.62 \mathrm{~mm}$ caliber.

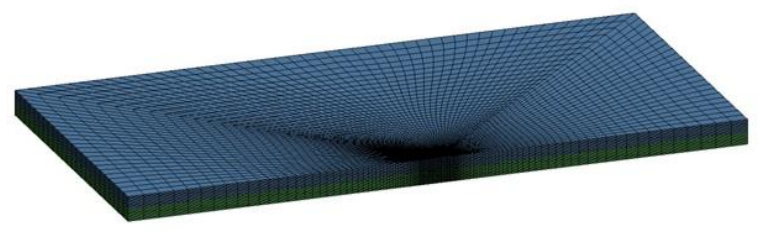

Figure 7. The mesh model with finite elements for the composite structure.

The structure of the finite element networks is presented in Table 1 . The meshed mathematical model is based on governing equations where the primary field functions are replaced by their approximations by means of nodal values collections and interpolation functions. 
Table 1. Structure of finite element networks.

\begin{tabular}{cccc}
\hline Ensemble & Components & Elements & Nodes \\
\hline & Core & 101,888 & 107,935 \\
& Case & 46,080 & 54,719 \\
Incendiary armor piercing bullet, & Bullet & 20,160 & 24,375 \\
7.62 mm caliber & Primer & 12,288 & 14,847 \\
& Propellant & 9216 & 10,735 \\
& Total & 189,632 & 212,611 \\
\hline \multirow{2}{*}{ HEA-steel composite structure } & HEA & 92,160 & 99,977 \\
& Steel & 92,160 & 99,977 \\
& Total & 184,320 & 199,954 \\
\hline TOTAL & & 373,952 & 412,565 \\
\hline
\end{tabular}

In the construction of the composite structures and bullet there are some typical materials, the models of which are described below.

a. The elastic model. With this model it is possible to model materials placed in required areas but only in elastic mode. For numerical simulation of the processes of dynamic plastic deformation through impact this model is of minor importance. From the mechanical point of view, three parameters are sufficient for defining the elastic linear isotropic material: E-Young modulus; $v$-Poisson coefficient; and $\rho$-density. In case of anisotropy, the elastic coefficients $E$ and $v$ are diversified on directions according to type.

b. The elasto-plastic model with linear hardening. It contains two parameters in addition to the elastic model: $\sigma_{y o}$-initial yield stress and $E_{t}$-tangential modulus.

To the elasto-plastic material model it can be attached a viscosity component, introduced by the factor $1+\left(\frac{\dot{\varepsilon}}{C}\right)^{\frac{1}{p}}$ established by Cowper și Symonds, where $\dot{\varepsilon}$ is the plastic strain-rate, $C$ and $p$-coefficients. This model of material is functional for isotropic or kinematic strengthening, but also works well in intermediate hardening cases.

c. The plasticity model with exponential hardening. For the plastic area, the yield stress on the surface $\sigma y$ can be expressed according to the equivalent plastic strain, $\varepsilon_{p}$, by the relation

$$
\sigma_{y}=A+B \varepsilon_{p}^{n}
$$

where: $A, B$, and $n$ are material constants.

Particularization for $n=1$ leads to the elasto-plastic model with linear hardening (bi-linear model).

d. The Johnson-Cook model. This plastic material model (flow sterss model) defines more accurately the flow stress $\sigma y$, taking into account, in addition to the effect of the equivalent plastic strain, the effects of the plastic strain rate and the temperature. The Johnson-Cook plasticity model is expressed by the equation $[39,40]$

$$
\sigma_{y}=\left(A+B \varepsilon_{p}^{n}\right)\left(1+C \ln \left(\frac{\dot{\dot{\varepsilon}_{p}}}{\dot{\dot{\varepsilon}_{0}}}\right)\right)\left(1-\left(\frac{T-T_{0}}{T_{m}-T_{0}}\right)^{m}\right)
$$

where: $A, B, C, n$, and $m$ are constant of material;

$T_{0}, T_{m}$ are the room temperature and melting temperature of the material, respectively; $\varepsilon_{p}$ - equivalent plastic strain; $\dot{\varepsilon_{p}}$-plastic strain rate; $\dot{\varepsilon_{0}}$-the effective plastic strain rate of the quasi-static test used to determine the yield and hardening parameters $A, B$ and $n$; $T$-local temperature in the material. 
The use of the plastic superior model implies the existence of a database acquired through complex material tests. In addition, the Johnson-Cook model is accompanied by a cumulative failure condition for effective plastic deformation.

The Johnson-Cook material model is applicable for high-speed deformation for many materials, including most metals. Typical applications for this model are similar to those modeled and simulated in the present work, and include ballistic penetration and impact processes.

The attention paid to the correct realization of the physical models, especially the material models needed in the numerical simulation process, is justified by the importance they have in achieving the objectives.

For each analysis variant, there were three virtual shootings conducted at different speeds using $7.62 \times 39 \mathrm{~mm}$ cal. incendiary armor piercing bullets.

The virtual testing was made using the same kind of projectile, with the following values of the specific parameters:

- $\quad$ Bullet caliber of $7.62 \times 39 \mathrm{~mm}$;

- $\quad$ Shooting angle of $0^{\circ}$;

- $\quad$ Incendiary perforating bullet weight of $7.67 \mathrm{~g}$;

- $\quad$ Steel core weight of $4 \mathrm{~g}$.

The setting of the speed bullets was done so that the effects on targets to be at the limit of perforating. The speeds of projectiles were adjusted during simulations to fall within these limits, different for each of the four types of structures analysed [38], namely:

A. Composite structure: HEA-STEEL welded by explosion

Testing speeds: $\mathrm{V}_{01}=900 \mathrm{~m} / \mathrm{s} ; \mathrm{V}_{02}=1000 \mathrm{~m} / \mathrm{s} ; \mathrm{V}_{03}=1100 \mathrm{~m} / \mathrm{s}$;

B. Composite structure: HEA-STEEL contour welded

Testing speeds: $\mathrm{V}_{01}=800 \mathrm{~m} / \mathrm{s} ; \mathrm{V}_{02}=900 \mathrm{~m} / \mathrm{s} ; \mathrm{V}_{03}=1000 \mathrm{~m} / \mathrm{s}$;

C. Composite structure: HEA-STEEL free on contour

Testing speeds: $\mathrm{V}_{01}=700 \mathrm{~m} / \mathrm{s} ; \mathrm{V}_{02}=800 \mathrm{~m} / \mathrm{s} ; \mathrm{V}_{03}=900 \mathrm{~m} / \mathrm{s}$;

D. Composite structure: HEA-STEEL-Duralumin sandwich type

Testing speeds: $\mathrm{V}_{01}=400 \mathrm{~m} / \mathrm{s} ; \mathrm{V}_{02}=500 \mathrm{~m} / \mathrm{s} ; \mathrm{V}_{03}=700 \mathrm{~m} / \mathrm{s}$.

The arrangement of composite structures with respect to the shooting direction is shown in Figures 8-11.

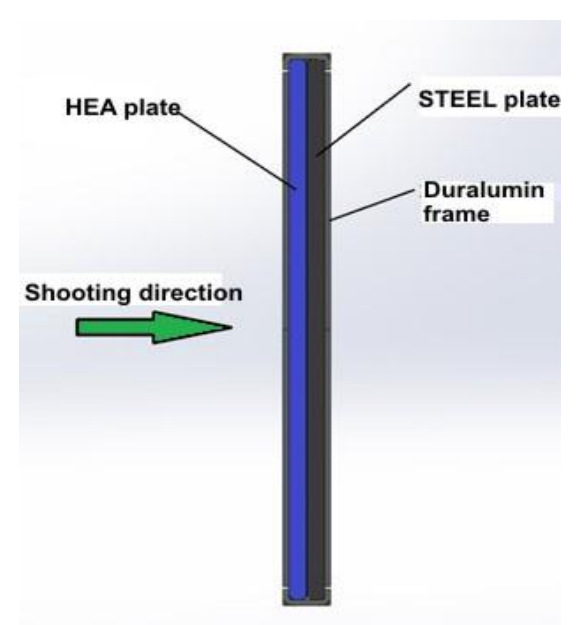

Figure 8. The shooting scheme for structure 1. 


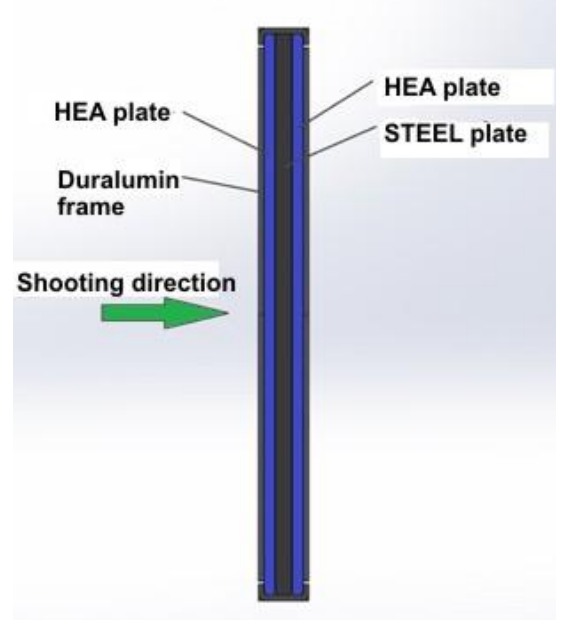

Figure 9. The shooting scheme for structure 3.

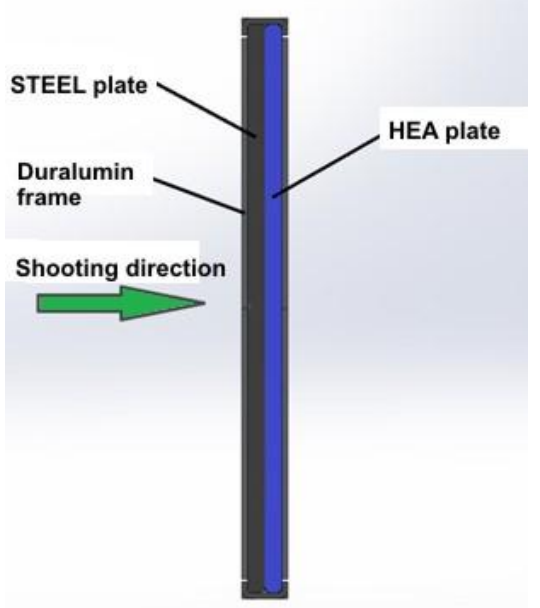

Figure 10. The shooting scheme for structure 2.

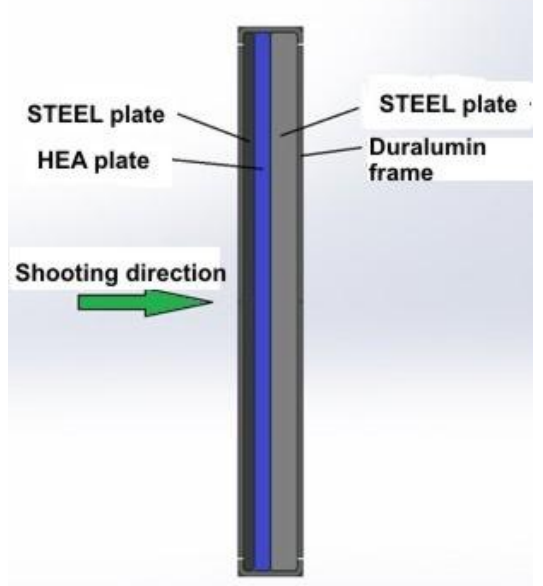

Figure 11. The shooting scheme for structure 4. 


\section{Results}

The mechanical characteristics of the materials included in the physical model designed for the numerical simulation of the performance of the HEA and steel plates dynamic stress resistant at impact with the incendiary bullet are given in Tables 2 and 3. The values were experimentally determined [38]. For materials that effectivelly participate in the impact energy exchange, both material models were given.

Table 2. Bi-linear elasto-plastic models.

\begin{tabular}{ccccccc}
\hline & & \multicolumn{5}{c}{ Mechanical Characteristics } \\
\cline { 3 - 7 } Material & Part & Density $\boldsymbol{\rho}$ & $\begin{array}{c}\text { Young } \\
\text { Modulus } E\end{array}$ & $\begin{array}{c}\text { Poisson } \\
\text { Coefficient } v\end{array}$ & $\begin{array}{c}\text { Yield } \\
\text { Stress } \sigma_{y}\end{array}$ & $\begin{array}{c}\text { Tangential } \\
\text { Modulus } E_{t}\end{array}$ \\
\cline { 3 - 7 } & & $\mathbf{K g} / \mathbf{m}^{3}$ & $\mathbf{M P a}$ & - & $\mathbf{M P a}$ & $\mathbf{M P a}$ \\
\hline Hardened steel & Core & 7850 & $2.1 \times 10^{5}$ & 0.3 & 2800 & 15,000 \\
Brass & Case & 8100 & $1.5 \times 10^{5}$ & 0.33 & 320 & 10,000 \\
Lead & Bullet & 11,200 & $1 \times 10^{5}$ & 0.37 & 50 & 100 \\
Low carbon steel & Primer & 7850 & $2.05 \times 10^{5}$ & 0.3 & 210 & 5000 \\
Pyrotechnic material & Propellant & 1200 & $1.0 \times 10^{3}$ & 0.49 & 10 & 20 \\
\hline HEA & Plate 1 & 7720 & $2.2 \times 10^{5}$ & 0.35 & 1550 & 5000 \\
Steel & Plate 2 & 7850 & $2.1 \times 10^{5}$ & 0.3 & 1250 & 3000 \\
\hline
\end{tabular}

Table 3. Johnson-Cook model.

\begin{tabular}{|c|c|c|c|c|c|c|c|c|c|c|c|}
\hline \multirow{4}{*}{$\begin{array}{l}\text { Metallic } \\
\text { Material }\end{array}$} & \multicolumn{11}{|c|}{ Mechanical Characteristics } \\
\hline & \multirow{2}{*}{ Density, $\rho$} & \multirow{2}{*}{$\begin{array}{l}\text { Transverse } \\
\text { Modulus, } G\end{array}$} & \multirow{2}{*}{$\begin{array}{c}\text { Young } \\
\text { Modulus, } E\end{array}$} & \multirow{2}{*}{$\begin{array}{c}\text { Poisson } \\
\text { Coefficient, } v\end{array}$} & \multicolumn{7}{|c|}{ Johnson-Cook Coefficients } \\
\hline & & & & & $A$ & $B$ & $n$ & $C$ & $m$ & $T_{\text {melt }}$ & $T_{0}$ \\
\hline & $\mathrm{Kg} / \mathrm{m}^{-3}$ & MPa & $\mathrm{MPa}$ & - & MPa & MPa & - & - & - & $\mathrm{K}$ & K \\
\hline HEA & 7720 & $0.81 \times 10^{5}$ & $2.2 \times 10^{5}$ & 0.35 & 1550 & 1200 & 0.24 & 0.032 & 1.00 & 1850 & 300 \\
\hline Armor steel & 7850 & $0.82 \times 10^{5}$ & $2.1 \times 10^{5}$ & 0.3 & 1250 & 3200 & 0.18 & 0.15 & 1.00 & 1763 & 300 \\
\hline
\end{tabular}

The proposed methodology for the modeling of the behavior at dynamic loads with high speed of the composite structures containing high entropy alloys used the finite element method (FEM) for which there is a wide range of software packages.

The methodology is formulated in general terms, common to all finite element programs. Therefore, it can be applied in programs that contain dynamic analysis modules, or in specialized programs such as AUTODYN or LS-DYNA $[15,38]$.

The results of the numerical simulations are shown in Figures 12-15, for different values of the shooting speed.

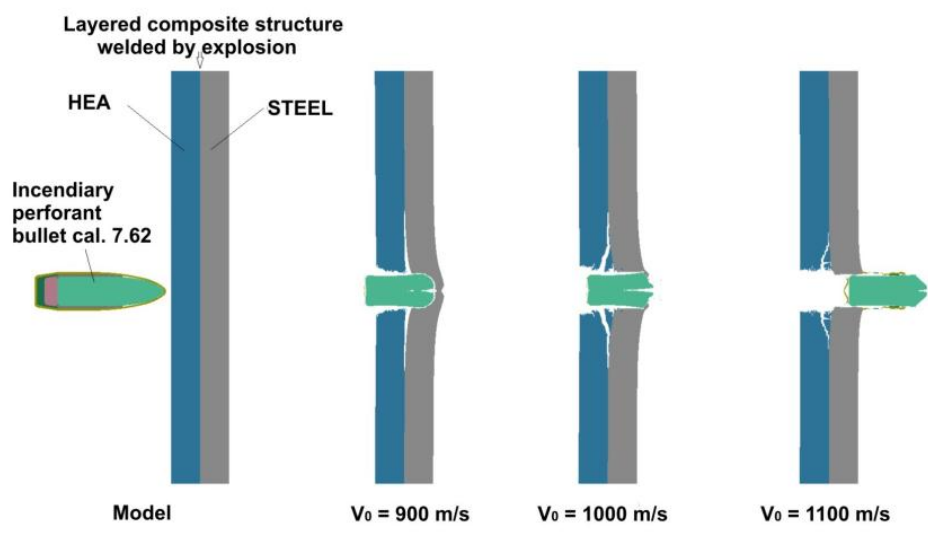

Figure 12. The behavior of the HEA-STEEL composite structure, welded by explosion, at impact with an incendiary armor piercing bullet (7.62 $\mathrm{mm}$ caliber) with different initial speeds. 


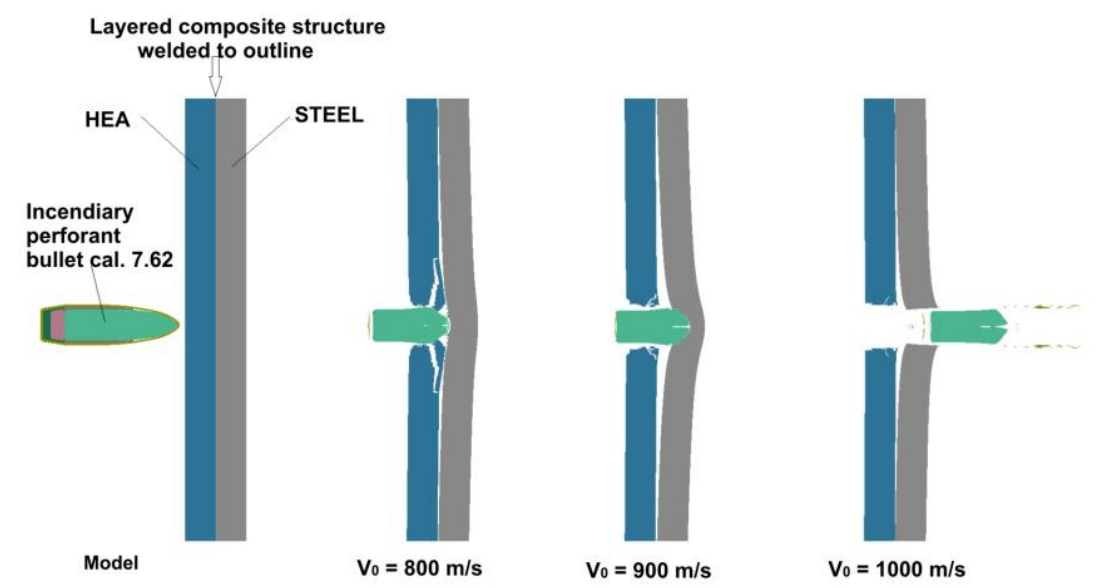

Figure 13. The behavior of the HEA-STEEL composite structure, welded to contour, at impact with an incendiary armor piercing bullet (7.62 $\mathrm{mm}$ caliber) with different initial speeds.

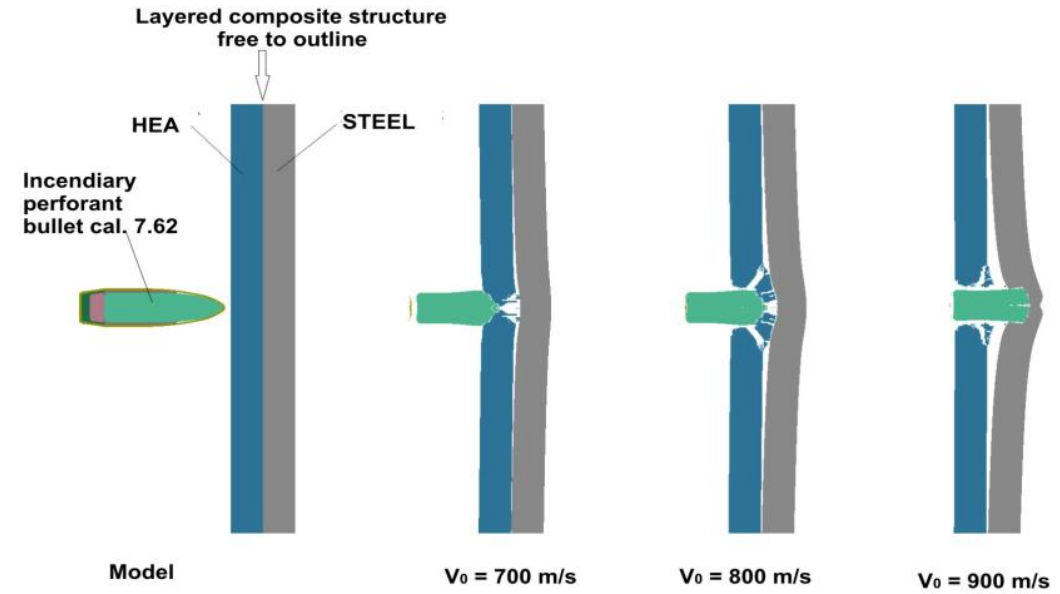

Figure 14. The behavior of the HEA-STEEL composite structure, free on contour, at impact with an incendiary armor piercing bullet (7.62 $\mathrm{mm}$ caliber) with different initial speeds.

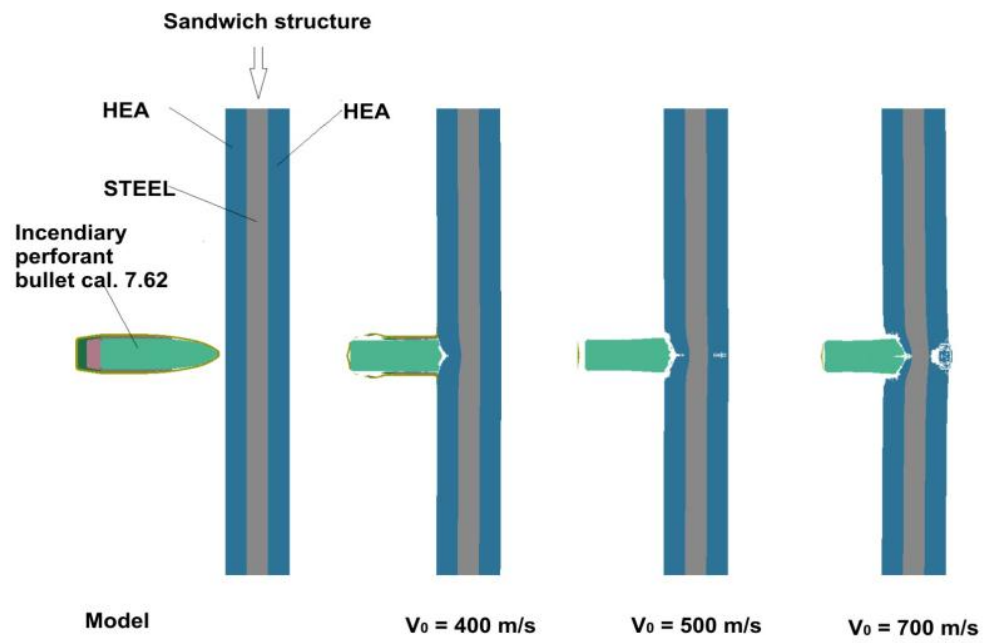

Figure 15. The behavior of the sandwich type composite structure at impact with an incendiary armor piercing bullet (7.62 $\mathrm{mm}$ caliber) with different initial speeds. 
The analysis of these representations emphasizes the role of correctly positioning the materials relative to the direction of impact.

\section{Discussion}

In Figure 12 is presented the behavior of the HEA-STEEL composite structure, welded by explosion, at impact with an incendiary armor piercing bullet $(7.62 \mathrm{~mm}$ caliber) with different initial speeds. The graph shows that at an impact velocity of $900 \mathrm{~m} / \mathrm{s}$ no perforation occurs, at an impact velocity of $1000 \mathrm{~m} / \mathrm{s}$ there is a partial perforation with material detachments on the back face of the structure. At a speed of $1100 \mathrm{~m} / \mathrm{s}$, there is a total perforation of the structure. The same structure but welded on contour (Figure 10) is less impact-resistant than previously shown, being fully perforated at an impact velocity of $1000 \mathrm{~m} / \mathrm{s}$.

The behavior of the structure free on the contour (Figure 11) shows that the perforation of the HEA plate occurs at the speed of $700 \mathrm{~m} / \mathrm{s}$, but for the steel plate the perforation does not occur even at a speed of $900 \mathrm{~m} / \mathrm{s}$.

In the case of the sandwich type structure (Figure 12), perforation occurs at much lower speeds (less than $500 \mathrm{~m} / \mathrm{s}$ ) than in previous cases.

The HEA-STEEL bimetallic composite structure provides good ballistic protection against $7.62 \times 39 \mathrm{~mm}$ cal. incendiary armor piercing bullets, especially if is obtained by explosion welding or brazing.

The structure of free plates or of plates bonded with organic adhesives presents dismantling risk during the impact of the projectile.

The placement order of the materials in the package to the direction of impact is of particular importance in the process. The tougher plate, even if it is less tenacious, receives the impact. The tenacious plate serves as support and receptor of fragments (splinters) formed from the first material.

The numerical simulations have shown that the composite sandwich structure with high entropy alloy plates placed outside is not viable. The rear plate can fragment on the axis of shooting because of the combination of shock waves and reflected waves. The solution can be improved if a layer made of polyamide fibers is placed behind the structure.

The analyzed variants show that the bimetallic structure welded by explosion or joined by brazing, forming a united block, provides the best ballistic protection. The bimetallic composite structure solution can be improved if light alloys are used instead of steel plates. This solution will be considered in the further development of the process.

Acknowledgments: The research work was financially supported by the Romanian National Program for Research within the framework of the Project No. PCCA 209/2012 "Composite structures resistant to dynamic loadings applied at high deformation speeds used in the field of collective protection-HEAMIL".

Author Contributions: Victor Geantă and Radu Ștefănoiu obtained the materials and wrote the paper; Ionelia Voiculescu performed the mechanical and characterization experiments; Daniel Dragnea, Teodora Zecheru and Liviu Matache designed and performed the experiments; Tudor Chereches, and Paul Lixandru analyzed the data.

Conflicts of Interest: The authors declare no conflict of interest.

\section{References}

1. Maweja, K.; Stumpf, W. The design of advanced performance high strength low-carbon martensitic armor steels, Microstructural considerations. Mater. Sci. Eng A 2008, 480, 160-166. [CrossRef]

2. Maweja, K.; Strumpf, W.E. Fracture and ballistic-induced phase transformation in tempered martensitic low-carbon armor steels. Mater. Sci. Eng A 2006, 432, 158-169. [CrossRef]

3. Hammond, R.I.; Proud, W.G. Does the pressure-induced a-e phase transition occur for all low-alloy steels? R. Soc. 2004, 460, 2959-2974. [CrossRef] 
4. Srivathsan, B.; Ramakrishnan, N. Ballistic performance maps for thick metallic armor. J. Mater. Process. Technol. 1999, 96, 81-91. [CrossRef]

5. Srivathsan, B.; Ramakrishnan, N. A ballistic performance index for thick metallic armor. Comput. Simul. Model. Eng. 1998, 3, 33-40.

6. Follensbee, P.S. Adiabatic shear localization in the dynamic punch test, part I: Experimental investigation. Int. J. Plast. 1999, 15, 241-262.

7. Jena, P.K.; Kumar, K.S.; Krishna, V.R.; Singh, A.K.; Bhat, T.B. Studies on the role of microstructure on performance of high strength armor steel. Eng. Fail. Anal. 2008, 15, 1088-1096. [CrossRef]

8. Verleysen, P.; Van Slycken, J.; Degriech, J.; De Cooman, B.C.; Samek, L. Impact-Dynamic Behaviour of AL-TRIP Steel. Available online: www.icf11.com/proceeding/EXTENDED/4108.pdf (accessed on 29 August 2017).

9. Voiculescu, I.; Geantă, V.; Ștefănoiu, R.; Pătroi, D.; Binchiciu, H. Influence of the chemical composition on the microstructure and microhardness of AlCrFeCoNi high entropy alloy. Rev. Chim. Buchar. 2013, 64, 1441-1444.

10. Zhang, Y.; Zuo, T.T.; Tang, Z.; Gao, M.C.; Dahmen, K.A.; Liaw, P.K.; Lu, Z.P. Microstructures and properties of high-entropy alloys. Prog. Mater. Sci. 2014, 61, 1-93. [CrossRef]

11. Gao, M.C.; Yeh, J.W.; Liaw, P.K.; Zhang, Y. High-Entropy Alloys: Fundamentals and Applications, 1st ed.; Springer International Publishing: Cham, Switzerland, 2016.

12. Miracle, D.B.; Senkov, O.N. A critical review of high entropy alloys and related concepts. Acta Mater. 2017, 122, 448-511. [CrossRef]

13. Geanta, V.; Chereches, T.; Lixandru, P.; Voiculescu, I.; Stefanoiu, R.; Dragnea, D.; Zecheru, T.; Matache, L. Simulation of Impact Phenomena on the Composite Structures Containing Ceramic Plates and High Entropy Alloys. In IOP Conference Series: Materials Science and Engineering, Proceedings of the International Conference on Innovative Research (ICIR Euroinvent), Iasi, Romania, 25-26 May 2017; IOP Publishing: Bristol, UK, 2017; Volume 209. [CrossRef]

14. Chung, D.D.L. Composite Materials, Science and Application, 2nd ed.; Springer: London, UK, 2010.

15. Kaminski, M.M. Computational Mechanics of Composite Materials; Springer: London, UK, 2005.

16. Wang, Y.P.; Li, B.S.; Ren, M.X.; Yang, C.; Fu, H.Z. Effects of creep on interfacial stresses of bonded structures. Mater. Sci. Eng. A Struct. 2008, 497, 471-478.

17. Geantă, V.; Voiculescu, I.; Ştefănoiu, R.; Savastru, D.; Csaki, I.; Patroi, D.; Leonat, L. Processing and characterization of advanced multi-element high entropy materials from AlCrFeCoNi system. Optoelectron. Adv. Mater. 2013, 7, 874-880.

18. Kao, Y.F.; Chen, T.J.; Chen, S.K.; Yeh, J.W. Microstructure and mechanical property of as-cast, -homogenized, and -deformed AlxCoCrFeNi $(0 \leq \mathrm{x} \leq 2)$ high-entropy alloys. J. Alloy. Compd. 2009, 488, 57-64. [CrossRef]

19. Shun, T.T.; Du, Y.C. Microstructure and tensile behaviors of FCC Al0.3CoCrFeNi high entropy alloy. J. Alloy. Compd. 2009, 479, 157-160. [CrossRef]

20. Ştefănoiu, R.; Geantă, V.; Voiculescu, I.; Csaki, I.; Ghiban, N. Researches regarding the influence of chemical composition on the properties of AlxCrFeCoNi alloys. Rev. Chim. Buchar. 2014, 65, 819-821.

21. Herbrand, M.; Adam, V.; Classen, M.; Kueres, D.; Hegger, J. Strenghtening of existing bridge structures for shear and bending with carbon textile-reinforced mortar. Materials 2017, 10, 1099. [CrossRef] [PubMed]

22. Wagner, C.; Bhatnagar, A. High Performance Woven and Non-woven Ballistic Materials for Flexible Vest. In Proceedings of the International Conference on Composite Materials (ICCM 14), San Diego, CA, USA, 14-18 July 2003.

23. Abrate, S. The dynamics of impact on composite structures. Key Eng. Mater. 1998, 141, 671-694.

24. Cantwell, W.J.; Morton, J. The impact resistance of composite materials-A review. Compos. Part B Eng. 1991, 22, 347-362. [CrossRef]

25. Classen, M.; Herbrand, M.; Kueres, D.; Hegger, J. Derivation of design rules for innovative shear connections in steel-concrete composites through the systematic use of non-linear finite element analysis (FEA). Struct. Concr. 2016, 17, 646-655. [CrossRef]

26. Frew, D.J.; Forrestal, M.J.; Chen, W. Pulse shaping techniques for testing elastic-plastic materials with a Split Hopkinson Pressure Bar. Exp. Mech. 2005, 45, 186-195. [CrossRef]

27. Govender, R.A.; Cloete, T.J.; Nurick, G.N. A numerical investigation of dispersion in Hopkinson Pressure Bar experiments. J. Phys. IV 2006, 134, 521-526. [CrossRef] 
28. Rotariu, A.; Bugaru, M.; Chereches, T. Finite elements method in SHPB developing process. In Proceedings of the 6th WSEAS International Conference on System Science and Simulation in Engineering, Venice, Italy, 21-23 November 2007.

29. Frew, D.J.; Forrestal, M.J.; Chen, W. Pulse shaping techniques for testing brittle materials with a Split Hopkinson Pressure Bar. Exp. Mech. 2001, 42, 93-106. [CrossRef]

30. Johnson, G.R.; Cook, W.H. A constitutive model and data for metals subjected to large strains, high strain rates and high temperatures. In Proceedings of the 7th International Symposium Ballistics, The Hague, The Netherlands, 19-21 April 1983; pp. 541-547.

31. Rotariu, A.; Chereches, T. Dedicated software application for split Hopkinson pressure bar and its critical assessment. In Proceedings of the 18th International DAAAM Symposium, Zadar, Croatia, 21-24 November 2007; DAAAM International: Vienna, Austria, 2007; pp. 651-653.

32. Gorham, D.A. A numerical method for the correction of dispersion in pressure bar signals. J. Phys. E Sci. Instrum. 1983, 16, 477. [CrossRef]

33. House, J.W.; Lewis, J.C.; Gillis, P.P.; Wilson, L.L. Estimation of flow stress under high rate plastic deformation. Int. J. Impact Eng. 1995, 2, 189-200. [CrossRef]

34. Erlich, D.C.; Chartagnac, P. Determination of dynamic flow curve of metals at ambient and elevated temperatures by rod impact techniques. J. Phys. 1985, 46, C5-455-C5-462. [CrossRef]

35. Dong, Y.; Feng, S.; Huang, G.; Liu, C.; Xiao, L.; Song, Q. Ballistic impact characteristics of flat-nose projectile penetrating concrete and soil compound target. Int. J. Nonlinear Sci. Numer. 2012, 13, 255-260. [CrossRef]

36. Huanran, W.; Canyuan, C.; Danian, C.; Chang, D.M. Dynamic constitutive behavior and fracture of lanthanum metal subjected to impact compression at different temperatures and impact tension. Int. J. Nonlinear Sci. Numer. 2013, 14, 21.

37. Wu, H.J.; Huang, F.L.; Wang, Y.N.; Duan, Z.P.; Shan, Y. Mass loss and nose shape change on ogive-nose steel projectiles during concrete penetration. Int. J. Nonlinear Sci. Numer. 2012, 13, 273-280. [CrossRef]

38. Structuri Compozite Rezistente la Solicitari Dinamice cu Viteze Mari de Deformare cu Aplicabilitate in Domeniul Protectiei Collective-Composite Structures Resistant at Dynamic Loadings Applied with High Deformation Speeds Used in the Field of Collective Protection-HEAMIL_PCCA 209/2012. Available online: www.uefiscdi.ro (accessed on 24 July 2017).

39. Preston, D.L.; Tonks, D.L.; Wallace, D.C. Model of plastic deformation for extreme loading conditions. J. Appl. Phys. 2003, 93. [CrossRef]

40. Optional Strain-Rate Forms for the Johnson Cook Constitutive Model and the Role of the Parameter Epsilon_01 ${ }^{1}$. Available online: http:/ /www.dynalook.com/european-conf-2007/optional-strain-rate-formsfor-the-johnson-cook.pdf (accessed on 2 November 2017). 